\title{
Sharing Music: Social and Communal Aspects of Concert-Going
}

\author{
LUCY K. DEARN, University of Sheffield
}

SARAH M. PRICE, University of Sheffield

\begin{abstract}
There is increasing interest in the academic community to better understand how concert audiences experience and value live classical music (Kolb 2000; Pitts 2005; Pitts et al. 2013; Radbourne, Glow \& Johanson 2013). Numerous authors have recognised the social value of concert attendance, especially important for infrequent and young attendees (Brown 2002; ACE 2004), however it is often assumed that frequent attendees are motivated by purely aesthetic reasons. Similarly, it has been acknowledged that a listener's experience of a concert is impacted by the presence of other audience members (Pitts 2005), yet there has been little research on the nature of the 'community' formed by a concert audience. In this paper, we wish to share our initial findings from our two collaborative doctoral awards in partnership with a regional chamber music promoter and a regional symphony orchestra. Through questionnaires, focus groups and interviews with audience members, we have sought to add additional understanding of concert attendance as a form of socialising, the short-term communal aspects of being 'inaudience', and the longer-term communities that surround cultural institutions, which can be seen to be displaying fan-like qualities. We aim to demonstrate that aesthetic pleasure is never the only motivating factor behind concert attendance, even for frequent attendees, as their selection of concerts and their listening experiences are always influenced by social interactions.
\end{abstract}

\section{KEYWORDS}

Audience; Classical Music; Concert; Community; Discussion 
Throughout the history of classical music, scholarly attention has been focused on the musical work, the composer, the performer and the concert hall; however, in recent years there has been a growing interest in the final element of the concert experience: the listener. Christopher Small's (1998) ethnography gives an account of the aesthetic and social experiences shared by audience members at a Western classical music concert. Paying attention to the listeners' experience was a positive step, however Small drew only on his personal experience rather than including other listeners' voices (Dobson \& Pitts 2011, 354). Some scholars have claimed that a listener's experience of a concert is impacted by the presence of other audience members in the concert hall environment (Clarke 2005; Pitts 2005), yet this is not absolutely accepted; Philip Auslander (2008) argues that 'the communal bond unifying such an audience is most likely to be little more that the common consumption of a particular performance commodity' (64).

In this paper, we explore these contradictions by using empirical research to investigate what significance the social and communal aspects of concert attendance might have for newcomers, infrequent attendees and regular audience members. We hope to demonstrate that the social context of concert attendance affects both the decision to attend a concert and the listening experience. Previous research has reduced socialising to a small number of categories, whereas our empirical research with audience members has revealed a spectrum of interactions; audience members socialise with companions, interact with other audience members, and can eventually become part of a listening community. Each of these will be explored in turn. In drawing attention to the impact of social context on even the most frequent attendees, we hope to readdress the dominance of aesthetics in our understanding of classical music audiences.

Since the publication of Small's ethnography, there has been growing body of empirical research on classical music audiences. Academic and commercial researchers have investigated the motivations and barriers to concert attendance (Baker 2007; ACE 2004; Earl 2001; Kolb 1998, 2000), the nature of the live concert experience (Gross 2013; Pitts 2005; O'Sullivan 2009; Burland \& Pitts 2014) and the way in which concerts are valued by audience members (Brown 2004b; Radbourne et al. 2013; Carnwath \& Brown 2014). In terms of social context, it has long been recognised that friends, family and teachers are extremely important in introducing children to live classical music, most notably by Pierre Bourdieu (1984). Furthermore, recent studies have explored the effect of adult socialisation as a route to attendance (Upright 2004; Van Berkel \& De Graaf 1995; Kane 2004). However, what is less certain is the extent to which socialising affects the decision to attend a particular concert. The opportunity to socialise at a concert has been identified as a particularly important motive for young people (Brown 2004a, 6; The Audience Agency 2013; Dobson \& Pitts 2012; Kolb 2000) and infrequent attendees (Baker 2007, 23; Brown 2002, 85; Arts Council England 2004, 38; Obalil 1999), both of whom are unlikely to attend alone. In the same studies, frequent attendees are depicted as comparatively disinterested in socialising. The impact of particular social interactions on concert selections has been explored in greater detail: Alan Brown (2004a) has suggested that within a group of attendees, there are 'initiators' who will select a concert and organise the group, and 'responders' who simply accept the invitation; Brown (2002, 85) and Pieter de Rooij (2013) have both demonstrated that married couples with similar tastes in music are likely to go to far more concerts than when tastes differ; and Stephanie Pitts and Christopher Spencer with colleagues have begun to explore how the feeling of belonging and community can contribute to an 
audience members' loyalty to an arts organisation (Pitts \& Spencer 2008; Pitts et al. 2013). On the whole, commercial researchers have more readily accepted the influence of socialising on concert selection.

During the concert itself, the communal nature of listening has been shown to affect the experience of a concert (O'Sullivan 2009; Gross 2013). It can enhance the performance, providing moments of sublimity, or detract from enjoyment, especially if other audience members are distracting (also discussed by Earl 2001; Baker 2007, 29; Burland \& Pitts 2014). Post-concert evaluation surveys often contain questions about the social experience (Carnwath \& Brown 2014). In these questionnaires, however, the diversity of interactions is reduced to primarily quantitative questions on: feelings of connection with the rest of the audience, a sense of belonging, and whether attendees discussed the event afterwards (see Brown \& Novak 2007, Brown \& Novak-Leonard 2013; Radbourne, Glow \& Johanson 2013). This reduction was addressed by Terry O'Sullivan's (2009) qualitative study into the nature of communal listening. He used in-depth focus groups to explore how audience members negotiated the private and communal experiences of listening in a concert. Through the application of economic models of 'consuming communities', he aimed to develop a 'more inflected view' of the audience as a community (212), but admitted that current models of communal consumption fail to accommodate the complexities of the social interactions of the audience (220). What is lacking in this literature is an exploration of the diversity and complexity of social experiences at concerts and the impact this has on both audience member's decision to attend and their listening experience.

Scholars of classical musical audiences have only recently turned attention to the social context of listening. Musicology has historically been focussed on the classical musical work as a text which was analysed for its formal structure and relation to cultural context of its composition. Despite what Georgina Born (2010) has called the 'practice turn' in musicology whereby ethnomusicologists and sociologists increasingly paid attention to the consumption of music, the text-centric history musicology has inherited has meant that the social context of classical music has often been neglected. This is not true of all musics; for example, the social value of music has been widely recognised in popular music. Furthermore, connections have also been made with this type of music and the formation of fan communities.

One aspect of socialising which we explore in this paper is the formation of listening communities. Varying definitions of community are found across disciplines, however we are defining community as a group of people joining together publicly over a shared passion, in the same geographical setting, who are united by a social matrix. This definition of community has roots in the work of David Hesmondhalgh (2013) who describes community in terms of 'publicness', which has two possible meanings, one of 'sociability among people who do not know each other' and the other 'a notion of political community grounded in citizenship' both of which can take co-present and mediated forms (85; also see Shank 2014 for connection between music and political communities). Hesmondhalgh suggests concerts allow for people that are 'co-present' to join in 'sociable publicness' (86). These types of communities allow for a sense of belonging whereby affiliations with community may contribute to the construction of a person's self-identity (DeNora 2000; Shank 2014). Developing a strong identity as a member of 
a community takes time, and this suggests inner structures of knowledge that needs to be learnt by newcomers, much like fan communities within popular music (Cavicchi 1998; Hills 2002). The term 'fan' is not often used to describe classical music audiences. Due to the fundamental differences in listening culture (classical listening behaviours are often silent, ostensibly passive and therefore anti-social compared to popular music's active and highly social audiences, see Sennett 2002 and Small 1998) it may not seem natural to view live classical performances as a potential site for fandom. Although fandom within classical music may present itself in different ways to popular music listening cultures, we aim to show that the same sense of affiliation can be found and classical music audiences can be considered as fans.

The application of fandom theory to the high arts is not without precedent: Claudio E. Benzecry $(2009 ; 2011)$ has found similar hierarchical structures within opera audiences. Benzecry's indepth ethnographic study of the audience of the Colon Opera House in Buenos Aires has demonstrated the potential for understanding opera audiences as a community, which can become a site for fandom. Benzecry's findings open up the opportunity for applying fandom theories to the high arts, and therefore, the related but different listening culture of classical music. By integrating himself with this very specific community, Benzecry is able to show how the social interactions that take place around this cultural event are integral to the listeners' experience.

Outside music, research with visitors to art galleries has considered the implications of socialising on engagement with visual art. Whether visitors attend alone or in a group has been shown to radically alter the aesthetic and learning experience (Debenedetti 2003; Packer \& Ballantyne 2005; Tröndle et al. 2012). Nevertheless, recent research with gallery visitors has challenged idea that visitors are either 'alone' or 'with companions'. Socialising is increasingly seen as a fluid experience between moments of socialising and moments of solitude (Debenedetti 2003; López Sintas, García Álvarez \& Pérez Rubiales, 2014). In this paper, we have adopted the term 'companions' to refer to audience members who plan to attend together, but similarly question the idea that all attendees can be categorised as 'alone' or 'with companions'. The frameworks developed in this more established field can be used to aid our understanding of classical music audiences.

\section{Investigating Audiences}

The data presented in this paper draws upon research conducted as part of Collaborative Doctoral Awards with two regional arts organisations: the City of Birmingham Symphony Orchestra (CBSO) and Music in the Round (MitR). The CBSO is a large symphony orchestra who perform over 100 concerts a year, specialising in large symphonic works from the eighteenth and nineteenth centuries. The majority of their concerts take place at the Symphony Hall, a purposebuilt concert venue which can seat over 2000 people. At this organisation, research participants were recruited via an online post-concert survey in which they were invited to take part in semistructured interviews with the researcher. The opt-in approach has a tendency to attract fervent supporters of the organisation, but the self-selection of participants also ensures that they are 
happy to talk freely and is typical of research in this field. Participants were selected in order to represent a range of levels of engagement (on-going, 26 participants to date).

The second case study was conducted with Sheffield-based chamber music promoter Music in the Round. Music in the Round presents over 100 concerts a year, doing so in a variety of venues in South Yorkshire, predominantly in Sheffield, and with partner venues in towns around the country. The research was conducted at one of MitR's partner venues, the newly-constructed multi-purpose arts venue, Cast in Doncaster. This research consisted of a longitudinal study over Cast's first year of opening and documented audience attitudes towards the new concert series, in particular, whether adapting to sitting 'in the round' changed the nature of audience community. The study tracked the experiences of a group regular attendees from the old venue ( 8 participants) and a group newcomers to the series (8 participants) through focus groups and postconcert questions via email. Regular attendees were recruited through the distribution of an eflyer by the organisation and newcomers invited through a local choral society as well as the regular audience members' e-flyer. At each concert over the year, a combination of questionnaires and shorter question-based comment cards were distributed to the whole audience, who were additionally invited to take part in an audience forum (30 participants). Participants at both organisations were predominantly White British and aged over 50, with a roughly equal split of men and women; this is representative of classical concert attendees in the UK (Chan et al. 2008). The qualitative discussions at both organisations were recorded, transcribed and analysed thematically by the respective researchers, before drawing comparisons between the two sets of data.

Although the data collected from the two population were conducted under different research design and conditions, all the data we present in this paper was sourced from highly qualitative methods and investigated the same question of the impact of the social context of concert-going. The two arts organisations used as case studies are similar in the repertory played (common practice period classical music), the traditional 'still and silent' listening culture (Sennett 2002) and their location in regional English cities. Their differences, namely in size, venue and musical form (orchestral and chamber music), are discussed throughout the paper where relevant to analysis. The benefit of combining data from two case studies is that we have been able to show commonalities in classical music attendees which transcend important differences in the nature of the arts organisations.

Our research builds on a number of developments within reception studies including viewing audiences as complex, heterogeneous populations who derive multiple meanings from cultural texts (Ang 1990; 1996; Morley 2003). We also draw on the ethnographic influences of new audience research, which attempts to understand the experience of individual audience members in relation to the context of their consumption, primarily through qualitative methodology (see Alasuutari 1999 for a summary of recent developments in this field). Using richly qualitative methods to better understand the arts experience has a more recent history in the study of copresent audiences for live performances (see Johanson 2013; Baxter 2010). We have therefore used interviews and focus groups to access attendees' personal accounts of concert-going. Although we recognise that using qualitative methods with small sample sizes limits the extent to 
which we can generalise from our results to the whole concert-going population, the value in this case study approach is in the richness and depth of material covered at these two organisations.

\section{Socialising with Companions}

The most noticeable form of socialising at a concert is attending as a group and spending time with companions. The universal categories of attending a concert 'alone' or 'with companions' conceal a spectrum of different social interactions. There is a vast difference between the experience of a couple who attend a concert every week and a friend who is using a spare ticket at the last minute, yet both would count as attending 'with companions'. Attending with companions is likely to influence the attendees' choice of concert. Companions differ not only in time commitments, budgets and practicalities such as travel time or mobility issues, they also have different knowledge, tastes and attitudes to risk with regards to programming. All of these must be negotiated in order for a group to attend. Even spouses who regularly attend together cannot be assumed to have homogenous tastes. Every married couple in our data mentioning some element of negotiation, for example these two subscribers at the CBSO:

(Husband) We get the advanced programme [...] and then, given time, we get our heads together and look through [...] and we have quite a long rabbit about it before we actually choose.

(Wife) And if I say 'no', he doesn't.

(Joint interview, July 2014)

Here, the husband was more adventurous but it was his wife who had the final say. Her husband was thus forced to be more conservative in his programme choice to accommodate her tastes. This supports Brown (2002, 11) and De Rooij's (2013) claims that dissonant tastes between spouses act as a barrier, ultimately leading to fewer attendances. Nevertheless, this was not the case for every couple. This CBSO subscriber likewise had different tastes compared to her husband, but had an alternative way of attending the concerts of her choice:

My husband, he just loves Beethoven, so I can always get him to come to those. [...] He's not as adventurous as I am in his tastes really [...] We go through their brochure together, but I'm the one who does the paperwork so I can manoeuvre it a bit!

(Interview, August 2014)

Her surreptitious way of ensuring her husband's attendance meant that their dissonant tastes did not act as a barrier, although there is no mention of whether this detracted from his enjoyment of the concert. She was able to make the final decision on their concert attendance because she 'does the paperwork'; in Brown's (2004a) framework, she is an 'initiator'. Brown's model is a useful way of understanding the dynamics of concert selection within a group, as often there is one person who leads the decision by choosing a concert and then proposes attendance to their companions, the 'responders'. Although Brown acknowledges in a footnote that these are not 
discrete categories, with the possibility of audience members being both or neither, he then goes on to discuss the 'psychological profile' of an initiator, describing them as 'natural' personality traits $(2004 a, 3)$. His terminology implies that these are static categories, whereas our data would suggest that initiators commonly adopt the role of responder in certain situations (though responders acting as initiators was rare). One CBSO subscriber, quoted below, is often an initiator, organising concert attendance for a large general-interest group, but still became a responder when invited by a friend to a rather unappealing programme of Verdi's Requiem:

I really didn't want to come, because I really think I don't like choral music very much. That's what I think. But in the spirit of all these great things about experimentation and new things, and also a friend said 'oh, it's the most incredible conductor and the most incredible choir and the most incredible orchestra; you will never, ever, ever see the Verdi [done better]!' And I thought, 'well, having been sold to me like that, I ought really to come'.

(Interview, September 2014)

Her reluctance is telling; as with the subscriber who 'manoeuvres' the paperwork, the responder is pushed outside their normal musical comfort zone. Moreover, initiators are also likely to select concerts more conservatively to accommodate the responder's tastes and take fewer risks that if they were attending alone. The programme choices of both initiators and responders are therefore influenced by their companions.

Depending on the accessibility of the music programmed, concerts may afford different opportunities for socialising. One thing that Brown (2004a) does not consider is that initiators must have a great deal of confidence in a concert in order to pitch it to a responder. As this CBSO subscriber explains, initiators are unlikely to invite companions to attend concerts they perceive as difficult or 'risky', in particular contemporary music:

Sometimes if it's a piece like Shostakovich - which is not everyone's cup of tea - or I have been to concerts with Webern which is a bit on the dodgy side, if that's the technical term for classical music! [laughs] [...] It's not one you say 'right, come along with me now'.

(Interview, August 2014)

Initiators are careful to choose concerts they believe responders will enjoy. Many used populist concerts as a site for socialising. Typified in the UK by Classic FM, populist classical programming consists of accessible and easily recognisable pieces, sometimes including film soundtracks and musical theatre, often programmed as shorter excerpts rather than full musical works. The concerts are generally more relaxed than traditional presentations, allowing audience members to talk quietly during the performance. ${ }^{1}$ The CBSO's populist series, the 'Friday Night

\footnotetext{
${ }^{1}$ The term 'populist' is more commonly used in political debate rather than cultural analysis. It describes anti-elitist tactics which are designed to appeal to the largest possible number of people. It is often used in a pejorative sense to imply a lack of integrity in favour of broad popularity. Populist presentation of classical music in recent years has been widely criticised on the same grounds (Johnson 2002). While the popularity of Classic FM and recorded music
} 
Classics', were used by a number of regular attendees to bring companions who were less interested in classical music, for example:

What we particularly like about the Friday concerts, it's music we can share with other people. [...] [A family member] isn't really into classical music [but] she'll enjoy a glitzy, fizzy concert.

(Interview, July 2014)

Our data suggests that while populist concerts do succeed in attracting new audiences, this is often mediated by regular attendees, who use these more accessible performances as a way to share their passion with non-attendees. This was echoed by a MitR attendee:

I think what makes it easier to come to things like this [populist concerts], if they have no interest before [...] if there is something they actually associate with or recognise, it will be popular things, because that's the way people ramp onto it. If they go into something that's very deep or difficult for them to understand, they are going to go to sleep and they are not going to come again.

(Audience forum, October 2014)

Populist concerts may therefore afford different social interactions to traditional concerts. The fact that attendees of traditional symphonic concerts will go to populist concerts to accommodate the tastes of their companions demonstrates the importance of socialising, even to frequent attendees.

The benefits of attending with companions must therefore outweigh any compromises in their choice of concert. As seen above, when participants were asked why they attended with companions, they often cited wanting to 'share' the experience. This usually consisted of experiencing the concert together, then discussing it afterwards. Audience members who had been to their first MitR concert at Cast were asked if they would talk about the concert after they left the hall. They said:

(a) I always speak about the venue.

(b) I do too.

(a) Yes, you talk about the evening; you talk about every part of it.

(Focus group, April 2014)

Participants at both organisations expressed how natural it was to participants to discuss an event afterwards. As has been noted in dance audience research, audience members often feel the need

has reignited this debate, this means of consuming classical music has a long history in which it is consistently positioned as less sophisticated than traditional concerts presenting whole musical works (DiMaggio 2004 discusses 'pops' concerts in relation to the establishment of high culture in the nineteenth century; for a discussion of lighter classical music and taste, see Bourdieu 1984). 
to discuss the event to make what is otherwise an ephemeral experience into something more concrete (Reason 2010, 392). Conversations help people to remember a concert. Attending with friends and family also provides the opportunity to discuss the concert not only during the interval, but also for months or years to come, in effect prolonging the experience. Conversations, in both the short-term and long-term, shape the way an attendee views an arts event. When our participants were describing their reactions to a concert, many spontaneously referred to conversations had with their companions. Sometimes this was to support their opinion, but often it was in contrast, as this subscriber at the CBSO described:

We went to Coventry to hear the [Britten's] War Requiem and I was just blown away by it but, you see, [my husband] wasn't that keen.

(Interview, August 2014)

Discussions become a way of processing an event; audience members take positions by aligning or contrasting their opinion with someone else. As Matthew Reason and Dee Reynolds have noted with dance audiences, talking about an event 'is a process whereby that experience is not merely reported but also constructed [...] the process of talking constructs meaning' (Reason \& Reynolds 2010, 51). Therefore the evaluation of an event is inextricably linked to social context and the benefit of attending with companions lies in these discussions.

\section{Socialising with other audience members and forming a community}

Attendees who go to concerts without companions can still have reflective conversations; they are able to talk and socialise with other audience members. Indeed, many attendees welcomed the opportunity to talk to other audience members, as discussed by these MitR newcomers:

(a) When I went out in the interval, I got talking to another lady - I don't know who she was - and her husband. But it is really quite nice, especially when you are on your own, that people do start to talk about the concert. Then you talk about other things and it's really very nice, that.

(b) It's that bonding, if you like; you are all here for a reason. I noticed some faces I know and it's that, sort of, I know why they're here, and it is just that common love of something, you know, and it's that shared experience.

(Focus group, April 2014)

Their shared experience opens up common ground for discussion and the potential for friendship formation, even if this is constrained to the four walls of the venue (Pitts \& Spencer 2008, 22930). Over many concert-sharing experiences with like-minded people, regular attendees become more familiar with each other and develop friendships, creating a matrix of social relationships across a regular audience. Repeated interactions between frequent attendees form the foundations of a listening community (Pitts \& Spencer 2008; O’Sullivan 2009; Benzecry 2011), whereby members of this community are choosing to share and value a particular cultural experience and 
develop a collective feeling of responsibility towards the future of their organisation. Previous authors have called for more understanding about the functions and working of classical music communities and how effectively a newcomer may integrate with them (Pitts \& Spencer 2008, 237).

This can be seen through the eyes of a CBSO subscriber who explained how the gradual process of talking to other audience members and over time building relationships helped him integrate with the pre-existing audience community.

My wife doesn't go to the concerts, so for the first probably two years, I'd walk around like a lemon upstairs, twiddling my fingers and thinking 'I'll pick up that magazine and read that book again' to while away the time, because I always arrive too early. But then gradually I've got to know a number of people who I can chat to. [Now] most concerts I come to, I speak to somebody I know.

(Interview, August 2014)

Newcomers were also able to integrate with the pre-existing community in Doncaster; by the end of the longitudinal study, it was hard to distinguish between the newcomers and regular audience members. Furthermore, over time, the sense of community developed through concert attendance only seemed to grow in importance:

It's just like meeting all the family when you come here.

(Focus group, April 2014)

Such a community holds great importance for me when attending Music in the Round concerts (as it does when I attend other events at Cast), because I feel that it enhances the intimate communal aspect of the musical experience.

(Email, October 2014)

Such a community is very important. It adds to the experience, as you can share and be stimulated and challenged by other people's views.

(Email, October 2014)

For those who have gained membership to this group, the sense of community is a positive dimension to the concert experience (Wenger 1998/2008). Over time, these friendships with other audience members can also be a rich source of learning, not only about how to listen but also about music more generally. This CBSO subscriber has the same seat at every concert, and described how:

There's a guy that sits next to me on my left and he's extremely knowledgeable about music. [...] he's enhanced my knowledge of music quite a lot.

(Interview, August 2014) 
Such knowledge transfer between more established audience members may also act as a learning resource for newcomers. The very act of listening as a member of an audience is something that newcomers are instantly aware of:

Looking at people's faces, I noticed a few people shutting their eyes and I thought 'oh, I'd not done that, I'll just shut my eyes and I'll listen with my eyes closed', you know so... but I kind of felt it was just the whole thing was one group, it was a gathering. We were all together on this, and it was like the people around were adding to it.

(Focus group, April 2014)

This MitR newcomer demonstrates how the social experience of communal listening might include learning to listen in different ways by watching those around you. However, not all newcomers have a positive and immersive experience and, in some cases, the presence of other audience members at MitR made newcomers unsure about the correctness of their own listening skills:

I concentrated more because I'm not familiar with listening to a lot of this type of music, so I'm a real newcomer getting used to it, and I found that I did concentrate more. I can get distracted.

(Focus group, April 2014)

Indeed, listening communities can make newcomers feel like outsiders compared to more experienced attendees. The behaviour of more experienced audience members therefore made this newcomer feel less confident and comfortable. This shows how a newcomer can feel like they are on the edge of established codes of behaviour, implying that the behaviour of the audience community was in some way structured and hierarchical. Benzecry similarly noted the internal structuring of an opera audience subculture, highlighting how members are able to transition through different stages of the structure, gaining greater 'rites of belonging' as they do $(2009,133)$. He describes how the less integrated members of the community will actively seek the 'advice of older fans' in order to climb within the hierarchy of the community $(2011,69)$, which is echoed by the MitR newcomers above, observing other attendees closing their eyes. Further to this, Daniel Cavicchi describes how, in the case of communities which are built around live events such as concerts, social hierarchy can also be seen purely through participation itself: 'concert going is as much about being seen as about seeing a performance; it involves forcing a view of oneself as similar to other fans and as different from ordinary audience members' (1998, Ch.6).

Like Benzecry's opera fanatics, our newcomers showed how integration with the community came through acquiring collectively valued knowledge: in the case of classical music, this included level of participation, knowledge of the musical works or loyalty to the arts organisation. Becoming part of a community is reliant not only on learning accepted behaviours, but also developing personal relationships with other regular attendees, as described by this audience member at MitR: 
I do feel part of a developing listening community, in that I see quite a few familiar faces at the concerts. There are people I recognise but don't know, others with whom I am on nodding terms and others with whom I can have a conversation.

(Email, October 2014)

It is interesting however, that this type of cultural knowledge seems to be bound together with levels of participation, such that amount of time one has been part of a fan culture may have more structural value than subject knowledge alone. Therefore, if becoming part of listening community takes time and an amount of learning, why are audience members willing to actively integrate and become accepted by one such community?

Fundamental to the formations of such listening communities, which people can choose to affiliate with, is the notion of shared tastes, as it allows people to be united around common and shared passions. The presence of core audience amongst concert series allow community members to feel part of the history of an organisation. Music in the Round and CBSO have been presenting classical music to audiences for many decades and this rich and varied history offers the respective communities opportunities to converse about past shared experiences, as two CBSO audience members describe:

And that's why I think socially, here, it's good to be able to talk. [...] It is, because I'm sitting with the same group of people and we discuss what's coming up and 'did you see so-and-so?'

(Interview, August 2014)

We still remember the sort of lectures we were given when the Symphony Hall first opened, [that] you mustn't even cough because it would be picked up by the microphones.

(Interview, August 2014)

Conversations about experiences of past concerts, anticipation for future events and organisational milestones gives heritage and purpose to this evolving community.

The sense of community may be valued by insiders, as well as offer an amount of financial security to arts organisations in the form of a core audience, but can be exclusive and off-putting to new attendees (O'Sullivan 2009, 219). As described by one MitR audience member, the community wants more than anything to pass community onto next generation so to ensure the preservation of classical music and a particular arts organisation that offers it:

I do think that recognition of other regular audience members helps me feel part of the core audience, because I know there'll always be someone to chat to before we go in (even if I don't actually know them), when we sit down and afterwards. Ideally, musical events are social occasions too and that fellow feeling will encourage newcomers to become regulars. 
(Email, October 2014)

The sense of moral responsibility to pass on history and traditions to the next generation is a key sign that an audience has formed community (O'Sullivan 2009) and is certainly true of regular attendees at both MitR and the CBSO. Many participants felt a personal responsibility to introduce new members and so grow the audience. A number of attendees had taken it upon themselves to encourage friends and family to attend, whether by acting as an advocate for the organisation or inviting them as companions:

I actively spread the word about 'community events' by posting publicity, encouraging people by word of mouth, and raving about the [MitR] concerts I've attended to all who'll listen!

(Email, October 2014)

The desire to maintain an organisation's audience and grow its community is an important reason for inviting companions, although it is worth noting that audience members are not always successful in finding new willing companions to bring. Listening communities therefore help financially and socially to ensure the future of an arts organisation.

Common across all our data was the importance that feeling part of a listening community held for members of this group, showing at least part of the value for these concert attendees was the communal and social aspects of concert-going. As described earlier, Auslander (2008) makes the argument that communities of live cultural events are in fact not communities at all, but just a group of people with the same consuming habits. ${ }^{2}$ The idea that audiences consume classical music like any other product has also been explored by Terry O'Sullivan (2009). However, O'Sullivan continues to state that the products people consume contribute to their self-identity, and common consumption, and therefore value of a particular cultural product allows people to go beyond personal differences and bond as a community. We suggest the two audiences explored in this study show the social context surrounding concert-going has far more significance for this community than mere common consumption.

\section{Implications}

Socialising at concerts provides attendees with the opportunity talk about a concert with someone who was also there. These conversations are a space for reflection, an opportunity to process their own reactions in comparison with others. Discussions with companions can continue when attendees leave the venue and carry on in the following days and months. For people who attend alone, immediate reactions can of course be shared with surrounding audience members, however, we have shown that development of an audience community also facilitates long-term reflection on concerts. Indeed, it is this long-term reflection which continually reinforces the sense of community at an organisation as it allows audience members to reach a consensus on a shared history and common values. The meaning derived from an event by an

\footnotetext{
${ }^{2}$ Auslander's views on audiences and the live cultural experience have been contested (see Barker 2003).
} 
attendee is mediated by discussions, and consequently, the aesthetic experience becomes inseparable from the social context.

This research therefore contributes to a rebalancing of attention in musicology away from analysis of music as text and towards a better understanding of how it is experienced by listeners. Appreciating classical music is all too often treated as an introspective activity; our data demonstrates that attending a concert can also be a communal and social experience. Within audience studies, the social context of concert-going is regularly acknowledged but rarely explored in any detail. The qualitative data we have collected shows the nuanced ways in which social context can impact on choice of concert, frequency of attendance, and feelings of belonging and comfort in the concert hall. We have shown the social context is not only important to those with a casual engagement with classical music but also many of the most frequent attendees as well. Our two case studies have contributed additional evidence to the presence of listening communities at classical music concerts. Furthermore, given the nature of the community and attendee's behaviour, we have suggested that these audiences may be understood as 'fans'. Talking to both frequent attendees and newcomers has begun to reveal how these communities are perceived by both those on the inside and outside.

The findings of this paper have implications for arts organisations as well as scholars. With evergrowing technological advancements, accessing high quality classical music away from the concert hall is becoming easier and cheaper than ever before, yet many people are actively choosing to experience this music as part of a live audience. The social dimension of concertgoing provides rich benefits and many that could not be received by solitary listening (Baker 2007, 29). Providing a space for discussion and reflection on a concert promotes the formation of friendships and community, particularly for those people who attend concerts without a companion. As friendships made at concerts often do not leave the venue (Pitts \& Spencer 2008, 230), they provide additional social reason to attend an organisation's concerts regularly. A sense of shared history felt by the community could also give an amount of social pressure to attend, so as not to be excluded from community's knowledge and possible future conversations.

In addition, listening communities can cause audience members to feel far more than a commercial relationship with a particular institution. As we have demonstrated, some feel like custodians of the organisation. Loyalty to a particular organisation not only encourages personal attendance but also fosters audience members to act as advocates, encouraging others to attend and bringing new members along as companions. However, promoting discussion and socialising at concerts should come with some caution. Some audience members have no desire to socialise beyond the companion they attend with, and other concert attendees will wish to optout of socialising altogether. ${ }^{3}$ The presence of a strong listening community can appear cliquey and off-putting to those on the outside. While for many people, concert-going functions as a

\footnotetext{
${ }^{3}$ Listening alone also has its benefits. Solitary listening can allow for escapism while still taking part in the world around you (see Bull 2005) and can impact on your everyday life and identity (see DeNora 2000). There has been little research into the potential benefits of attending a concert alone, but Tröndle et al.'s (2012) recent study of art galleries suggests visitors can experience deeper aesthetic connections to the artwork if they are viewing it on their own. More research is needed into the potential benefits of solitary attendance.
} 
place to meet like-minded people, arts organisations face the difficult task accommodating those who choose not to participate.

Despite showing the importance of discussion for audience members' experience of a concert, surprisingly little is known about the nature of these conversations; further investigations are needed into the discussions had in the interval and immediately after an event. The moments when the performance stops are particularly important for live classical music, as audience members usually remain still and silent during the performance, making these two places the first opportunities to express their reactions. Dobson and Sloboda (2014) have conducted post-concert discussions between audience and musicians to better understand how an audience experiences the concert, but this is still an artificial environment. Much could be learnt from documenting and analysing the natural conversations that arise. In addition, little is known about how the nature of a venue impacts on the sociability of a performance. Whether a concert hall is on a single floor or multiple levels, whether there is a foyer or bar, whether it has seating is unreserved or chosen at the time of purchase could all influence how audience members interact and whether a community begins to form. In demonstrating the diversity of social interactions at concerts, we have also highlighted how much more work there is to be done.

This paper has shown that classical music audiences are not homogeneous, but instead use concerts as a site for a spectrum of social interactions. From being alone in an audience, to spending time with companions, to becoming a fully-fledged community member, no audience member is confined to one point on the spectrum of social interaction. Even within the space of one concert, attendees move fluidly between different social situations. Across two very different organisations and amongst a set of participants with varying levels of engagement we have found that a recurring theme of the importance of social and communal experiences that is not dictated by their level of engagement. Much more could be learnt through investigating larger groups of attendees at a range of organisations, because even within our relatively small sample, the diversity of social experiences at concerts, from the micro to the macro, has been illuminated. 


\section{Acknowledgements}

We would like to thank the many participants for giving up their time and talking so freely about their own experiences of concert-going. This research would not have been possible without the help and support of the CBSO and MitR, who have given us access to their audiences and kindly allowed us to share our findings. We would also like to thank Professor Stephanie Pitts and Dr Jonathan Gross for many lively discussions and for their helpful comments on earlier drafts of this paper. We are grateful to the editor and two anonymous reviewers for their helpful comments.

An earlier version of this paper was presented at the Royal Musical Association Research Students' Conference, University of Bristol, 8-10 January 2015.

\section{References}

Alasuutari, P. (1999) 'Introduction: Three Phases of Reception’ P. Alasuutari (ed.), Rethinking the Media Audience: The New Agenda, London: Sage, pp. 1-21.

Ang, I. (1990) 'Culture and Communication: Towards an Ethnographic Critique of Media Consumption in the Transnational Media System', European Journal of Communication, 5/2, 239-260.

Ang, I. (1996) Living Room Wars: Rethinking Media Audiences for a Postmodern World. London: Routledge.

Arts Council England \& Morton Smyth Ltd (2004) 'Not for the Likes of You. Phase Two Final Report, Document A: How to Reach a Broader Audience', [online]. Available at http://culturehive.co.uk/wp-content/uploads/2013/04/Not-for-the-Likes-of-You.pdf. Accessed 19 April 2014.

The Audience Agency (2013) 'Top Tips on Developing Young Audiences', [online]. Available at http://www.theaudienceagency.org/media/PDFResources/ResourcesSection/Top Tips for Developing Young Audiences.pdf. Accessed 30 January 2014.

Auslander, P. (2008) Liveness: Performance in a Mediatised Culture (2 ${ }^{\text {nd }}$ ed.), London: Routledge.

Baker, T. (2007) 'Stop Re-Inventing the Wheel', [online]. Available at http://culturehive.co.uk/wp-content/uploads/2013/04/Stop-Reinventing-the-Wheel-Guide-toClassical-Music-Audiences.pdf. Accessed 17 November 2013.

Barker, M. (2003) 'Crash, Theatre Audiences, and the Idea of "Liveness”', Studies in Theatre and Performance, 23/1, 21-39. 
Baxter, L. (2010) 'From Luxury to Necessity: the Changing Role of Qualitative Research in the Arts', in D. O'Reilly \& F. Kerrigan (eds), Marketing the Arts: A Fresh Approach, Abingdon: Routledge, pp. 121-140.

Benzecry, C.E. (2009) 'Becoming a Fan: On the Seductions of Opera', Qualitative Sociology, 32, 131-151.

Benzecry, C.E. (2011) The Opera Fanatic: Ethnography of an Obsession, Chicago and London: The University of Chicago Press.

Berkel, M. van, \& N de Graaf (1995) 'Husband's and Wife's Culture Participation and their Levels of Education: A Case of Male Dominance?', Acta Sociologica, 38/2, 131-149.

Born, G. (2010) 'For a Relational Musicology: Music and Interdisciplinarity, Beyond the Practice Turn', Journal of the Royal Musical Association, 135/2, 205-243.

Bourdieu, P. (1984) Distinction: A Social Critique of the Judgement of Taste, Cambridge, MA: Harvard University Press.

Brown, A.S. (2002) 'Classical Music Consumer Segmentation Study: How Americans Relate to Classical Music and Their Local Orchestras', [online]. Available at http://www.polyphonic.org/wpcontent/uploads/2012/04/2002 Classical Music Consumer Report.pdf. Accessed 8 March 2014.

Brown, A.S. (2004a) 'Initiators and Responders: A New Way to View Orchestra Audiences', [online]. Available at

http://www.knightfoundation.org/media/uploads/publication pdfs/2004 Magic of Music Iss ues Brief 4.pdf. Accessed 8 March 2014.

Brown, A.S. (2004b) 'The Values Study: Rediscovering the Meaning and Value of Arts Participant', [online]. Available at http://www.giarts.org/sites/default/files/values-studyrediscovering-the-meaning-and-value-of-arts-participation.pdf. Accessed 31 January 2014.

Brown, A. S. \& Novak, J.L. (2007) 'Assessing the Intrinsic Impacts of a Live Performance', [online]. http://www.wolfbrown.com/mups downloads/Impact Study Final Version full.pdf. Accessed 30 January 2014.

Brown, A.S. \& Novak-Leonard, J.L. (2013) 'Measuring the Intrinsic Impacts of Arts Attendance', Cultural Trends, 22/3-4, 223-233.

Bull, M. (2005) 'No Dead Air! The iPod and the Culture of Mobile Listening', Leisure studies, 24/4, 343-356.

Burland, K. \& Pitts, S. (eds) (2014) Coughing and Clapping: Investigating Audience Experience, Aldershot: Ashgate. 
Carnwath, J.D. \& Brown, A.S. (2014) 'Understanding the Value and Impacts of Cultural Experiences' [online]. Available at http://www.artscouncil.org.uk/media/uploads/pdf/Understanding the value and impacts of cultural experiences.pdf. Accessed 30 July 2014.

Cavicchi, D. (1998) Tramps like us: Music \& Meaning among Springsteen Fans [Kindle ebook], New York \& Oxford: Oxford University Press.

Chan, T. W., Goldthorpe, J., Keaney, E., \& Oskala, A. (2008) 'Attendance at Music Events and Participation in Musical Activities in England: Findings from the Taking Part Survey', [online]. Available at http://www.artscouncil.org.uk/media/uploads/TakingPart 0506 Music.pdf. Accessed 31 January 2014.

Clarke, E.F. (2005) Ways of Listening: An Ecological Approach to the Perception of Musical Meaning, Oxford: Oxford University Press.

Debenedetti, S. (2003) 'Investigating the Role of Companions in the Art Museum Experience', International Journal of Arts Management, 5/3, 52-63.

DeNora, T. (2000) Music in Everyday Life, Cambridge: Cambridge University Press.

DiMaggio, P. (2004) 'Cultural Entrepreneurship in Nineteenth-Century Boston, Part II: The Classification and Framing of American Art' in B. M. Carbonell (ed.), Museum Studies: An Anthology of Contexts, Oxford: Blackwell, pp. 461-483.

Dobson, M.C. \& Pitts, S.E. (2012) 'Classical Cult or Learning Community? Exploring New Audience Members' Social and Musical Responses to First-time Concert Attendance', Ethnomusicology Forum, 20/3, 37-41.

Dobson, M.C. \& Sloboda, J. (2014) 'Staying Behind: Explorations in Post-performance Musician-Audience Dialogue' in K. Burland \& S. Pitts (eds), Coughing and Clapping: Investigating Audience Experience, Aldershot: Ashgate, pp. 159-174.

Earl, P.E. (2001) 'Simon's Travel Theorem and the Demand for Live Music', Journal of Economic Psychology, 22/3, 335-358.

Gross, J. (2013) 'Concert Going in Everyday Life: An Ethnography of Still and Silent Listening at the BBC Proms', PhD Thesis, Birkbeck College, University of London.

Hesmondhalgh, D. (2013) Why Music Matters, Chichester: Wiley Blackwell.

Hills, M. (2002) Fan Cultures, London: Routledge.

Johanson, K. (2013) 'Listening to the Audience: Methods for a New Era of Audience Research', in J. Radbourne, H. Glow, \& K. Johanson (eds), The Audience Experience: a Critical Analysis of Audiences in the Performing Arts, Bristol: Intellect, pp. 159-173. 
Johnson, J. (2002). Who Needs Classical Music? Cultural Choice and Musical Value, Oxford University Press.

Kane, D. (2004) 'A Network Approach to the Puzzle of Women's Cultural Participation', Poetics 32/2, 105-127.

Kolb, B.M. (2000) 'You Call This Fun? Reactions of Young First-time Attendees to a Classical Concert', Music Industry Issues and Studies, 1/1, 13-28.

Kolb, B.M. (1998) 'Classical Music Concerts Can Be Fun: The Success of BBC Proms', International Journal of Arts Management, 1/1, 16-23.

López Sintas, J., García Álvarez, E., \& Pérez Rubiales, E. (2014) 'Art Museum Visitors: Interaction Strategies for Sharing Experiences', Museum Management and Curatorship, 29/3, 241-259.

Morley, D. (2003) Television, Audiences and Cultural Studies, London: Routledge.

Obalil, D.L. (1999) 'Barriers and Motivations to Increased Arts Usage Among Medium and Light Users', [online]. Available at http://beta.artsbizc.s466.sureserver.com/files/BarriersAndMotivations.pdf. Accessed 1 March 2014.

O'Sullivan, T. (2009) 'All Together Now: A Symphony Orchestra Audience as a Consuming Community', Consumption Markets \& Culture, 12/3, 209-223.

Packer, J. \& Ballantyne, R. (2005) 'Solitary vs. Shared: Exploring the Social Dimension of Museum Learning', Curator: The Museum Journal, 48/2, 177-192.

Pitts, S. E. (2005) 'What Makes an Audience? Investigating the Roles and Experiences of Listeners at a Chamber Music Festival', Music and Letters, 86/2, 257-269.

Pitts, S. E. \& Spencer, C.P. (2008) 'Loyalty and Longevity in Audience Listening: Investigating Experiences of Attendance at a Chamber Music Festival', Music and Letters, 89/2, 227-238.

Pitts, S.E., Dobson, M.C, Gee, K., \& Spencer, C.P. (2013) 'Views of an Audience: Understanding the Orchestral Concert Experience from Player and Listener Perspectives', Participations, 10/2, 65-95.

Radbourne, J., Glow, H., \& Johanson, K. (2013) 'Knowing and Measuring the Audience Experience', in J. Radbourne, H. Glow, \& K. Johanson (eds), The Audience Experience: A Critical Analysis of Audiences in the Performing Arts, Bristol: Intellect, pp. 1-13.

Reason, M. \& Reynolds, D. (2010) 'Kinesthesia, Empathy, and Related Pleasures: An Inquiry into Audience Experiences of Watching Dance', Dance Research Journal, 42/2, 75. 
Reason, M. (2010) 'Watching Dance, Drawing the Experience and Visual Knowledge', Forum for Modern Language Studies, 46/4, 391-414.

Rooij, P. de (2013) 'Customer Loyalty to Performing Arts Venues: Between Routines and Coincidence', PhD Thesis, Tilburg University.

Sennett, R. (2002) The Fall of the Public Man, London: Penguin.

Shank, B. (2014) The Political Force of Musical Beauty, Durham and London: Duke University Press.

Small, C. (1998) Musicking: The Meanings of Performing and Listening, Middletown, CT: Wesleyan University Press.

Tröndle, M., Wintzerith, S., Wäspe, R., \& Tschacher, W. (2012) 'A Museum for the TwentyFirst Century: The Influence of "Sociality" on Art Reception in Museum Space', Museum Management and Curatorship, 27/5, 461-486.

Upright, C. (2004) 'Social Capital and Cultural Participation: Spousal Influences on Attendance at Arts Events', Poetics, 32/2, 129-143.

Wenger, E. (1998/2008) Communities of Practice: Learning, Meaning, and Identity, Cambridge: Cambridge University Press.

Lucy Dearn and Sarah Price are both third-year AHRC Collaborative Doctoral Award Students with the Sheffield Performer and Audience Research Centre at the University of Sheffield (http://www.sparc.dept.shef.ac.uk) under the supervision of Professor Stephanie Pitts. They are working in partnership with regional chamber music promoter, Music in the Round and the City of Birmingham Symphony Orchestra respectively to conduct research with classical music audiences.

Email: 1kdearn1@ sheffield.ac.uk (Lucy) and smprice1@ sheffield.ac.uk (Sarah) 